\title{
Facilitating Factors for HIV/AIDS Stigma and Discrimination, and Political Priority for its Reduction among Local Government Chairmen in Osun State, Nigeria
}

\author{
Ademola Lukman Adelekan ${ }^{1}$, Elizabeth Ronami Edoni ${ }^{2}$ \\ ${ }^{I}$ (Health Promotion and Education Department, College of Medicine/University of Ibadan, Nigeria) \\ ${ }_{2}^{2}$ (Department of Community Health, College of Health Sciences/Niger Delta University, Wilberforce Island, \\ Nigeria)
}

\begin{abstract}
In Nigeria, the failure of the government to adequately regulate and fund the health system has been documented to contribute to stigmatization attitudes towards people living with HIV/AIDS (PLWHA). This study therefore designed to explore facilitating factors for HIV/AIDS Stigma and political priority for its reduction among Local Government Chairmen (LGC).

This cross-sectional study was conducted in Local Government Areas (LGAs) in Osun State, Nigeria. All the twenty-six consenting out of thirty LGC were interviewed using In-Depth Interview guide. The analysis was done thematically by reading through the transcribed interviews.

Many of the respondents were aware that HIV is high in Nigeria but did not know the significant of this extent. Only few respondents said they could perform certain activities with PLWHA. HIV/AIDS was among the prioritized health programmes in many of the local government but there was no budget for PLWHA. The main perceived strategies suggested by respondents for controlling HIV/AIDS included advocacy to policy makers on increase in allocation to HIV/AIDS control and breaking of confidentially that is attached to HIV/AIDS.

There was no adequate political attention for reducing HIV/AIDS stigma at the local government level. Appropriate HIV/AIDS sensitization programme should be instituted for the respondents'.
\end{abstract}

Keywords: Chairmen, HIV/AIDS, Local Government, Political Priority, Stigma and Discrimination

\section{Introduction}

HIV-related stigma and discrimination have been acknowledged as an impediment to mitigating the HIV epidemic since its early days, yet programming and activities to reduce stigma and discrimination have been given much less attention than other aspects of the epidemic. Right from the beginning, the HIV/AIDS epidemic has been accompanied by an epidemic of fear, ignorance, and denial, leading to stigmatisation of and discrimination against people with HIV/AIDS and their family members [1]. HIV/AIDS related stigma and the resulting discriminatory acts create circumstances that fuel the spread of HIV [2]. The fear of being identified with HIV prevents people from learning their sero-status, changing unsafe behaviour, and caring for people living with HIV/AIDS. A study in Botswana and Zambia found that stigma against HIV-positive people and fear of mistreatment prevented people from participating in voluntary counselling and testing and programmes to prevent mother-to-child transmission [3].

HIV/AIDS-related stigma and discrimination have had a substantial impact on people living with HIV/AIDS (PLHA) and those at risk of HIV infection. HIV-related stigma has been shown to act as a barrier to HIV Voluntary Counseling and Testing (VCT) as well as to the effectiveness of prevention and care services [4, $5,6,7,8]$. Often these barriers are most profound in settings with limited access to antiretroviral therapies (ARVs). Previous research demonstrated that access to ARVs reduces HIV/AIDS-related stigma [9, 10, 11]. As ARV programs continue to scale-up and access to therapies increases worldwide, it is crucial to consider the role of HIV/AIDS related stigma in the design and implementation of effective prevention and treatment programs. The political attention to address the problem of stigma have been scientifically documented to be lacking and this study therefore designed to explore facilitating factors for HIV/AIDS Stigma and political priority for its reduction among Local Government Chairmen in Osun State, Nigeria.

\section{Methods}

\subsection{Study design}

This descriptive cross-sectional study was carried out among local government chairmen in Osun State, Nigeria. The study sought to explore facilitating factors for HIV/AIDS Stigma and political priority for its reduction. 


\subsection{Study Area}

Osun State is an inland state in south-western Nigeria. Its capital is Osogbo. It is bounded in the north by Kwara State, in the east partly by Ekiti State and partly by Ondo State, in the south by Ogun State and in the west by Oyo State. Osun State is home to several of Nigeria's most famous landmarks, including the campus of Obafemi Awolowo University, Nigeria's pre-eminent institution of higher learning. The university is also located in the ancient town of Ile-Ifẹ, an important early center of political and religious development for Yoruba culture. The modern Osun State was created in 1991 from part of the old Oyo State. The state's name is derived from the River Osun, the venerated natural spring that is the manifestation of the Yoruba goddess of the same name. Osun State is divided into three federal senatorial districts, each of which is composed of two administrative zones. The state consists of thirty Local Government Areas, the primary (third tier) unit of government in Nigeria.

\subsection{Method of Data Collection}

The study was a descriptive qualitative study that utilized in-depth interviews. Qualitative study method was chosen because of its usefulness in exploration of people's knowledge, views and experiences. The other advantage of qualitative methods is that they can be participatory, democratic and empowering. Use of open-ended questions in in-depth-interviews allowed the participants to express themselves in their own vocabulary that would be different in close ended questions characteristic of quantitative method.

\subsection{Data Collection Procedure}

We interviewed all the twenty six consenting out of thirty local government Chairmen in Osun State, Nigeria. All the interviews took place at the respondents' office in their local government at the times convenient for them after advanced booking. A brief explanation of the aim of the study and confidentiality related issues kicked off the interview where participants were assured that their names would not appear in the study report. At the end of the interview, debriefing was carried out and some quotations were read back to the participants especially on some of the important points. Generally interviews were carried out in a harmonious, friendly and open atmosphere. Each interview lasted about 30-60 minutes. During the interview, data was recorded with tape recorder.

\subsection{Study Instrument}

A pre-tested In-Depth-Interview (IDI) guide was used to obtain relevant information on facilitating factors for HIV/AIDS Stigma and political priority for its reduction among Local Government Chairmen in Osun State, Nigeria. The IDI guide was developed by the authors based on information in the literature on HIV/AIDS. The guide was pre-tested among LGC in Oyo State because of similarities in socio-demographic characteristics of Oyo and Osun States. Five LGC were used for the pre-test and they were selected in Ibadan and Ogbomoso.

\subsection{Sampling technique}

Purposive sampling technique was adopted to select respondents' they were used for this study. This means that respondents were selected because of their position as local government chairmen.

\subsection{Data Analysis}

The analysis was done by reading through the transcribed interviews and listening to the audio records in order to get all major discussions during the interviews. The key ideas and emerging themes were identified and themes from different groups were thematically pooled together and integrated into common themes. This was then followed by generation of concepts that were used to organize the presentation of the findings.

\subsection{Demographic characteristics}

\section{Results}

Twenty-six local government chairmen participated in these in-depth interviews and all of them were males. The mean age was $43 \pm 4.2$ years. All the respondents' have at least secondary school certificate and they were all married.

\subsection{Awareness of magnitude of HIV/AIDS in Nigeria}

Majority of the respondents were aware that prevalence of HIV is high in Nigeria but they did not know the significant of this extent. All the respondents did not know the current prevalence rate of HIV/AIDS in Nigeria. Many of the respondents reported knowing at least one person in their community with HIV and few respondents stated that at least a member of their staff has been diagnosed with HIV. All the respondents did not 
know the number of people in their community that are living with HIV. Most respondents said they first heard about AIDS from the media, particularly radio and newspapers. Other sources of information on HIV/AIDS among respondents were friends, relatives and medical personnel.

\subsection{Knowledge of HIV/AIDS}

Only two of the respondents can state the full meaning of HIV/AIDS. The modes of transmission mentioned by respondents were casual sexual intercourse or having multiple sexual partners, sharing skin piercing instruments, from mother to child and blood transfusion. In transmission from mother to child, fifteen respondents thought that it can be transmitted through the placenta, six thought during the delivery and other five thought that HIV can be transmitted by breast feeding. Seven of the respondents were not aware that healthy looking person could be infected with HIV and three respondents of the respondents thought HIV could be transmitted by insects bite and by sharing meal with PLWHA. All the respondents mentioned fever as one of the symptoms of HIV/AIDS while continuous diarrhoea and loss of weight were reported symptoms by five and twenty-two respondents respectively.

When respondents were asked to identify precautions against HIV/AIDS they knew, the best known methods were avoiding unprotected sex, loyalty to one partner, avoidance of sharing skin piercing instruments and blood transfusions and condom use. In a related question, the respondents were asked what they considered to be the most important precaution against AIDS transmission: the majority of them considered avoidance of casual sex the most important. The two next most important precautions were the use of condoms, and avoiding blood transfusions.

An overwhelming majority of Nigerians associate HIV/AIDS transmission with sexual relations, and especially with casual or multiple partners. When asked the respondents whether they thought the fear of HIV/AIDS infection had limited casual sex in their community, only two respondents who knew about AIDS agreed. Twenty of them thought that the fear of AIDS had not limited casual sexual relations, and four respondents said they did not know.

Information was further sought on the respondents' personal experience with extramarital sex in relation to their perceptions of the risk of AIDS. Nearly half of respondents said they had never had extramarital relations. Six had modified their sexual behaviour because of the fear of AIDS, three have become more selective of their extramarital sexual partners, three have stopped extramarital affairs completely and two said they now used condoms in extramarital encounters while the remaining two respondents did not respond to the question.

\subsection{HIV voluntary counselling and testing among respondents}

Only twelve of the respondents reported to have ever under gone HIV testing. Out of these respondents, only seven under-gone testing on voluntary basis, while the rest of the respondents' did it in a response to a physician request.

\subsection{Respondents Attitudes toward PLWHA}

In other to determine the extent of discrimination of respondents to PLWHA, some questions were asked from the respondents about whether they could perform certain activities with PLWHA. Only few of the respondents' said they could sleep on the same bed with them. Some respondents claimed they could shake hands, hug and shared the same toilet with them while remaining respondents said they cannot not do all those things with PLWHA. Ten out of the respondents also believed that PLWHA should not have children believing that they could not live to take care of those children and they would not want to inherit liability as community leaders. More so when the belief is that there is no drug that can cure the disease and that those infected would eventually die. This position was corroborate by a respondent who says

"There is no need to have children since they will not be able to take care of them. Unfortunately, extended family members are not ready to combine such children with theirs because of the economic condition of the country".

Some of these respondents also thought children of PLWHA could also be infected if there is no good medical care especially for those in rural communities where there is little or no access to prevention of Mother to Child Transmission service All the respondents are willing to care for relative with HIV/AIDS but only few respondents are willing to take meal with PLWHA. All the respondents' agreed to allow HIV infected staff to continue working in their local government but some respondents added a condition that such staff should not have reached the level of AIDS where such staff might be getting sick often.

On the willingness to keep a secret if family member is infected with HIV, all the respondents' agreed to keep such secret because they know what attitude their community members can have towards such person. A respondents said 'I will have to keep it a secret because in my community, people often see those that are living 
with HIV as people that are promiscuous due to the fact that most of the people that have HIV got it from sexual intercourse'.

A respondent said 'it is necessary to keep it secret because HIV is not like any other disease that one can openly announced that one family member have because people will beginning to suspect that maybe am also positive especially if such family members were not from extended family'.

Another respondent said 'I will surely keep it a secret because I know people will stigmatized against such person and even myself I cannot even predict what my attitude would be towards such person because it easier said than done'

\subsection{Supports for PLWHA}

All the respondents said currently there is no specific budget provision for PLWHA at the local government level but there are provision for HIV/AIDS prevention and control programmes in local government. All the local government have HIV/AIDS manager who is saddle with the responsibility of planning and implementing HIV/AIDS programme for the people within such local government. All the local government have various source of funds for HIV/AIDS programme and such funds are usually directed to behavioural change programme due to the poor level of knowledge of their community members especially those at the rural areas. Respondents were further asked to know if there are programme in place to support PLWHA to face the challenges of stigma and discrimination but nearly all the respondents said there was no stigma reduction programme in their local government but they do more of community sensitization to increase people's level of knowledge on this disease.

\subsection{Prioritized health programmes in local government and factors used in prioritizing a problem.}

Many of the respondents mentioned HIV/AIDS control and Immunization. Some respondents further mentioned sickle cell eradication and construction of maternity centre while another few mentioned tuberculosis and leprosy control.

On the factors used in prioritizing health programmes in local government, few of the respondents said because they get external financial support for these programmes and because these health programmes were given a priority by the state government. A respondent said 'prioritizing a problem has to do with the self interest of the Local Government Chairman who is the head of local government, other executive members and the Legislators'. Respondents were also asked the state of political attention for reducing HIV/AIDS in their local governments and many respondents said there was no adequate political attention against this disease due to inadequate financial resources and low prevalence of HIV/AIDS in their State. Few respondents said local government do not have capacity to give a problem a priority that they only work on the order of the state government. A respondent specifically said 'I don't see HIV/AIDS as a challenge in my local government because the prevalence is low and I don't think it should be given any political attention'

\subsection{What government should do to reduce HIV/AIDS in Nigeria?}

All the respondents suggested public health education, increase allocation to health and women empowerment. Other strategies suggested were advocacy to policy makers on increase in allocation to HIV/AIDS control, information and education campaigns to community members, treatment and care for PLWHA and breaking of confidentially that is attached to HIV/AIDS. A respondent further added that 'many of the health care workers in local government who are programme implementers are not vast in what they do, that many of them also lack appropriate knowledge and skill for planning and implementation of health programmes'. Another respondent said 'we have adequate manpower that are professionals in Nigeria only that they are handicap with necessary resources that can be used for their programme'. The respondent therefore recommends adequate resources to health in other to build man power of their staff.

Few respondents said 'promotion of girl child education will have a significant impact in reducing HIVIAIDS in Nigeria since majority of the PLWHA are women'. Another respondent said 'more non governmental organisation should be encouraged especially in rural areas to implement sensitization programme for rural people where majority of people there have no formal education. He further added that 'there should be appropriate legislation against PLWHA who are deliberately infecting other people with this infection especially women who have sex relation with people with aim of transferring this infection'. Majority of the respondents further said that 'constitution amendment will also be necessary so that local government leaders can have their autonomy to write their budget and prioritize a problem themselves'

\section{Discussion}

Many of the respondents reported media as major source of information on HIV/AIDS. This is similar to the finding of $[12,13,14]$ where television was found to be the most important information source on HIV/AIDS. 
Misconceptions that HIV can be transmitted by insect bite and sharing meal with PLWHA may tend to promote negative attitudes towards PLWHA. This might be indicative of the fact that negative response and attitudes towards PLWHA are strongly linked to general levels of knowledge about HIV and AIDS and, in particular, to the causes of AIDS and routes of HIV transmission [15]. Respondents considered avoidance of casual sex the most important precaution against HIV transmission. This is in accord with the finding of [16] where majority of respondents suggested having only one sexual partner as a way of reducing the chance of HIV/AIDS.

Only few of the respondents' had ever undergone HIV testing and previous research has suggested that fear of stigmatization and discrimination is a barrier to HIV testing in diverse settings $[17,18]$ and that individuals who had never been tested for HIV were more likely to express stigmatizing attitudes towards PLWHA [19, 20, 21]. Similarly, stigma has been cited as a primary barrier to using VCT services in Botswana, South Africa, Tanzania, Thailand, Uganda, and Zimbabwe [22, 23, 24].

Respondents' showed a negative attitude towards PLWHA. This is similar to the finding of [16] where many of the respondents showed behavioural discrimination or stigma to PLWHA or show a negative attitude. Other numerous household surveys and other probability-sampled surveys reported extensive stigmatizing attitudes among the general population across all samples studied in settings as diverse as China, US, Hong Kong, South Africa, Jamaica, Brazil, Nigeria, Thailand, Tanzania, Zimbabwe, Burkina Faso, Zambia, and Ghana $[25,26,27,28,29,30,31,32,33,34,35,36,37,38,39,40,41,42,43,44]$

Few respondents agreed to allow infected staff to continue working in their local government on the condition that such staff should not have reached the level of AIDS. Rini and Najmah (2011) also reported that many of their respondents' disagreed that person with AIDS should be allowed to continue teaching. Few respondents' specifically said they cannot sleep on the same bed, shake hands and even shared the same toilet with PLWHA and this may likely affect their physical and psychological aspects of life. The results of this study also revealed that even though HIV/AIDS was among the prioritized health programmes in all the local government, there is no specific budget to support PLWHA.

\section{Conclusion}

The perception of how HIV/AIDS was acquired is critically important on how people will treat a People Living with HIV/AIDS. The results of this study also show that regardless of intensive public campaigns relating to various aspects of HIV/AIDS, including its transmission, the messages have not quite reached a large majority of people in the country especially the political leaders who are the decision makers in the country. The Information, Education, and Communication campaigns and regular training workshop for political leaders on HIV/AIDS need to be intensified to dispel some of the prevailing misconceptions about HIV/AIDS transmission and to give this disease a priority especially the stigma aspect of the disease.

\section{References}

[1] International Center for Research on Women. Addressing HIV-Related Stigma and Resulting Discrimination in Africa: A ThreeCountry Study in Ethiopia, Tanzania, and Zambia. Information Bulletin, March, 2002.

[2] Busza, J. Literature Review: Challenging HIV-Related Stigma and Discrimination in Southeast Asia: Past Successes and Future Priorities. 1999. Population Council Horizons.

[3] Nyblade, L. and Field, M. L. Women, Communities, and the Prevention of Mother-to-Child Transmission of HIV: Issues and Findings from Community Research in Botswana and Zambia. 2000. Washington, DC: ICRW.

[4] Boer, H., \& Emons, P. A. Accurate and inaccurate HIV transmission beliefs, stigmatizing and HIV protection motivation in northern Thailand. AIDS Care, 2004,16(2), 167-176.

[5] Carr, R. L., \& Gramling, L. F. Stigma: a health barrier for women with HIV/AIDS. The Journal of the Association of Nurses in AIDS Care, 2004, 15(5), 30-39.

[6] Doherty, T., Chopra, M., Nkonki, L., Jackson, D., \& Greiner, T. Effect of the HIV epidemic on infant feeding in South Africa: "when they see me coming with the tins they laugh at me". Bulletin of the World Health Organization, 2006, 84(2), 90-96.

[7] Kalichman, S. C., \& Simbayi, L. C. HIV testing attitudes, AIDS stigma, and voluntary HIV counselling and testing in a black township in Cape Town, South Africa. Sexually Transmitted Infections, 2003. 79(6), 442-447.

[8] Turan, J. M., Miller, S., Bukusi, E. A., Sande, J., \& Cohen, C. R. HIV/AIDS and maternity care in Kenya: how fears of stigma and discrimination affect uptake and provision of labor and delivery services. AIDS Care, 2008, 20(8), 938-945.

[9] Abadia-Barrero, C. E., \& Castro, A. Experiences of stigma and access to HAART in children and adolescents living with HIV/AIDS in Brazil. Social Science \& Medicine, 2006, 62(5), 1219-1228.

[10] Castro, A., \& Farmer, P. Understanding and addressing AIDS-related stigma: from anthropological theory to clinical practice in Haiti. American Journal of Public Health, 2005, 95(1), 53-59.

[11] Wolfe, W. R., Weiser, S. D., Leiter, K., Steward, W. T., Percy-de Korte, F., Phaladze, N., et al. The impact of universal access to antiretroviral therapy on HIV stigma in Botswana. American Journal of Public Health, 2008, 98(10), 1865-1871.

[12] Pötsönen R \& Kontula O. Adolescents' knowledge and attitudes concerning HIV infection and HIV-infected persons: how a survey and focus group discussions are suited for researching adolescents' HIV/AIDS knowledge and attitudes. Health Education Research 1999, 14(4): 473-484.

[13] Yoo K, Lee SH, Kwon BE, Chung S \& Kim S. HIV/AIDS knowledge, attitudes, related behaviours, and sources of information among Korean adolescents. Journal of School Health, 2005, 75(10): 393-399.

[14] Serlo K \& Aavarinne H. Attitudes of university students towards HIV/AIDS. Journal of Advanced Nursing, 1998, 29(2): 463-470. 
[15] Bharat S, Aggleton P, Tyrer P. India: HIV and AIDS related Discrimination, Stigmatization and Denial. Geneva, 2001, Switzerland: UNAIDS.

[16] Rini Mutahar and Najmah Yenni. Determinants of Indonesian People Attitudes Towards People Living with HIV/AIDS. International Journal of Public Health Research Special Issue, 2011, pp (224-228)

[17] Day, J. H., Miyamura, K., Grant, A. D., Leeuw, A., Munsamy, J., Baggaley, R.. Attitudes to HIV voluntary counselling and testing among mineworkers in South Africa: will availability of antiretroviral therapy encourage testing? AIDS Care, 2003, 15(5), 665672.

[18] Ma, W., Detels, R., Feng, Y., Wu, Z., Shen, L., Li, Y. Acceptance of and barriers to voluntary HIV counselling and testing among adults in Guizhou province, China. AIDS, 2007, 21(Suppl. 8), S129-S135.

[19] Hutchinson, P. L., \& Mahlalela, X. Utilization of voluntary counseling and testing services in the eastern cape, South Africa. AIDS Care, 2006, 18(5), 446-455.

[20] Kalichman, S. C., \& Simbayi, L. C. HIV testing attitudes, AIDS stigma, and voluntary HIV counselling and testing in a black township in Cape Town, South Africa. Sexually Transmitted Infections, 2003, 79(6), 442-447.

[21] Pulerwitz, J., Michaelis, A. P., Lippman, S. A., Chinaglia, M., \& Diaz, J. HIV related stigma, service utilization, and status disclosure among truck drivers crossing the southern borders in Brazil. AIDS Care, 2008, 20(7), 764-770.

[22] Wolfe, W. R., S. D. Weiser, D. R. Bangsberg, I. Thior, J. M. Makhema, D. B. Dickinson, K. F. Mompati and R. G. Marlink. "Effects of HIV-related stigma among an early sample of patients receiving antiretroviral therapy in Botswana." AIDS Care 2006, 18: $931-933$.

[23] Bwambale, F. M., S. N. Ssali, S. Byaruhanga, J. N. Kalyango and C. A. S. Karamagi. "Voluntary HIV counselling and testing among men in rural western Uganda: Implications for HIV prevention." BMC Public Health 2008, 8: 263-263.

[24] Khumalo-Sakutukwa, G., S. Morin, K. Fritz, E. Charlebois, H. van Rooyen, A. Chingono, P. Modiba, K. Mrumbi, S. Visrutaratna, B. Singh, M. Sweat, D. Celentano and T. Coates (2008). "Project Accept (HPTN 043): a community-based intervention to reduce HIV incidence in populations at risk for HIV in sub-Saharan Africa and Thailand." Journal of AIDS, 2008, 49(4): 422-431.

[25] Chen, J., M. K. Choe, S. Chen and S. Zhang. "Community Environment and HIV/AIDS-Related Stigma in China." AIDS Education and Prevention, 2005, 17(1): 1-11.

[26] Lau, J. T. F. and H. Y. Tsui. "Discriminatory attitudes towards people living with HIV/AIDS and associated factors: a population based study in the Chinese general population." Sexually Transmitted Infections 2005, 81(2): 113-119.

[27] Hongjie, L., H. Zhi, L. Xiaoming, B. Stanton, S. Naar-King and Y. Hongmei. "Understanding Interrelationships Among HIVRelated Stigma, Concern About HIV Infection, and Intent to Disclose HIV Serostatus: A Pretestâ€"Posttest Study in a Rural Area of Eastern China." AIDS Patient Care \& STDs, 2006, 20: 133-142.

[28] Mak, W. W. S., P. K. H. Mo, R. Y. M. Cheung, J. Woo, F. M. Cheung and D. Lee. "Comparative Stigma of HIV/AIDS, SARS, and Tuberculosis in Hong Kong." Social science \& medicine, 2006, 63(7): 1912-1922.

[29] Maughan-Brown, B. G. "Attitudes towards people with HIV/AIDS: Stigma and its determinants amongst young adults in Cape Town, South Africa." South African Review of Sociology, 2006, 37: 165-188.

[30] Norman, L. R., R. Carr and J. Jimenez. "Sexual stigma and sympathy: Attitudes toward persons living with HIV in Jamaica." Culture, Health \& Sexuality, 2006,_8(5): 423-433.

[31] Visser, M. J., J. D. Makin and K. Lehobye. "Stigmatizing attitudes of the community towards people living with HIV/AIDS." Journal of Community \& Applied Social Psychology, 2006, 16: 42-58.

[32] Chan, K. Y., Y. Yang, K. L. Zhang and D. D. Reidpath. "Disentangling the stigma of HIV/AIDS from the stigmas of drugs use, commercial sex and commercial blood donation - a factorial survey of medical students in China." BMC Public Health, 2007, 7: 12.

[33] Chen, J., M. K. Choe, S. Chen and S. Zhang. "The effects of individual- and community-level knowledge, beliefs, and fear on stigmatization of people living with HIV/AIDS in China." Aids Care-Psychological and Socio-Medical Aspects of Aids/Hiv 2007, 19(5): 666-673.

[34] Lau, J. T. F. and H. Y. Tsui. "Comparing the magnitude of discriminatory attitudes toward people living with HIV/AIDS and toward people with mental illness in the Hong Kong general population." Health education research, 2007, 22(1): $139-152$.

[35] Ndinda, C., C. Chimbwete, N. McGrath and R. Pool. "Community attitudes towards individuals living with HIV in rural KwaZulu-Natal, South Africa." AIDS Care, 2007, 19: 92-101.

[36] Bunn, J. Y., S. E. Solomon, S. E. Varni, C. T. Miller, R. L. Forehand and T. Ashikaga. "Urban-Rural Differences in Motivation to Control Prejudice toward People with HIV/AIDS: The Impact of Perceived Identifiability in the Community." Journal of Rural Health, 2008,_24(3): 285-291.

[37] Chiu, J., J. Grobbelaar and T. Kershaw. "HIV-Related Stigma and Social Capital in South Africa." AIDS Education and Prevention, 2008,_20(6): 519-530.

[38] Garcia, S., M. A. H. Koyama and S. Grp Estudos Populacao. "Stigma, discrimination and HIV/AIDS in the Brazilian context, 1998 and 2005." Revista De Saude Publica 2008, 42: 11.

[39] Stein, J. A. and L. Li. "Measuring HIV-related Stigma Among Chinese Service Providers: Confirmatory Factor Analysis of a Multidimensional Scale." AIDS and Behavior 2008,12(5): 789-795.

[40] Babalola, S., A. Fatusi and J. Anyanti. "Media saturation, communication exposure and HIV stigma in Nigeria." Social Science and Medicine, 2009,68(8): 1513-1520.

[41] Genberg, B. L., Z. Hlavka, K. A. Konda, S. Maman, S. Chariyalertsak, A. Chingono, J. Mbwambo, P. Modiba, H. Van Rooyen and D. D. Celentano. "A comparison of HIV/AIDS-related stigma in four countries: Negative attitudes and perceived acts of discrimination towards people living with HIV/AIDS." Social Science and Medicine, 2009,_68(12): 2279-2287.

[42] Norman, L. R., S. Abreu, E. Candelaria and A. Sala. "The effect of sympathy on discriminatory attitudes toward persons living with HIV/AIDS in Puerto Rico: a hierarchical analysis of women living in public housing." AIDS Care, 2009, 21(2): 140-149.

[43] Stephenson, R. "Community factors shaping HIV-related stigma among young people in three African countries." Aids CarePsychological and Socio-Medical Aspects of Aids/Hiv 2009, 21(4): 403-410.

[44] Visser, M. J., J. D. Makin, A. Vandormael, K. J. Sikkema and B. W. C. Forsyth. "HIV/AIDS stigma in a South African community." AIDS Care, 2009, 21(2): 197-206. 